\title{
Superficial tribological transformation of a ferritic stainless steel by dynamic microindentation
}

\author{
H. Boudoukha ${ }^{1^{*}}$, S. Djabi ${ }^{2}$ \\ ${ }^{1}$ Laboratory Non-Metallic Materials, URMES, IOMP-UFA, Sétif, Algeria; ${ }^{*}$ Corresponding Author: hasbou2001@yahoo.fr \\ ${ }^{2}$ Laboratory of Photonic Systems and Nonlinear Optics, IOMP-UFA, Sétif, Algeria
}

Received 16 March 2013; revised 16 April 2013; accepted 24 April 2013

Copyright (C) 2013 H. Boudoukha, S. Djabi. This is an open access article distributed under the Creative Commons Attribution License, which permits unrestricted use, distribution, and reproduction in any medium, provided the original work is properly cited.

\begin{abstract}
Currently, the stainless steel starts to widen its fields of application in an extraordinary way in medicine and surgery, in the domestic utensils (flatware) and in heavy industry (petrochemistry, nuclear industry and transport). This work consists of making an experimental study on a type of ferritic stainless steel having undergone the test of the microindentation at controlled load and knowing the Superficial Tribological Transformations (STT) caused by this test. It is supposed that it is a simulation with the damages caused on the stainless steels which are in the environment (the effect of hail) or in industry (shot-blasting of the turbines). The analysis of the repeated shocks is based on the mechanical characterization (microhardness, microstructures of the impacts) and geometrical to see the evolution of the diameter and depth of the impacts according to the number of shocks (cycles of impact), in order to know the plastic deformation.
\end{abstract}

Keywords: Microindentation; Hv Microhardness; Work Hardening; Plastic Deformation

\section{INTRODUCTION}

The lifespan of a mechanical set depends on the lifespan of each of its elements, which are submitted in service to a state of complex stresses in the time (for example: external disturbances, vibrations). Indeed, a material submitted to repeatedly mechanical solicitations can break prematurely, even if the levels of constraints reached are lower than those supported in monotonous loading: it is the phenomenon of tiredness. In order to study the mechanical behavior in cyclic fatigue of the ferritic stainless steel, initially, it is necessary to determine the extent of the security zone of the field of plasticity where the rupture does not occur even after a high number of cycles. Then, it is necessary to characterize the evolution of the geometry and the microhardness of the prints carried out by the shocks repeated with an aim of limiting their effects, by adjusting the parameters of development and thus extending the security zone [1-7]. The ferritic stainless steels are characterized by the absence of ferrite-austenite transformation and consequently, they are not hardened by a heat treatment but only by work hardening [8-10].

\section{DYNAMIC MICROINDENTATION WITH CONTROLLED LOAD}

\subsection{Mechanics of Indentation}

Depending on the shape of the indenter, it is possible to make a spherical penetrant or a pointed penetrant. Figure 1 shows various types of the indenter.

\subsection{Micropercutor with Controlled Impact Energy}

The damage process is simulated with a numerical control marking machine which is the micropercutor intended for the marking of alphabetical natures or logotypes on the parts. The characters are obtained by alignment of the successive impacts of a stylus on the part to be marked. These impacts are achieved by means of a cermet indenter with tip radius varying from $200 \mu \mathrm{m}$ to $20 \mathrm{~mm}$. Thus it becomes possible to carry out, in a reliable and reproducible way, impacts with controlled energy, therefore to try to simulate the effects of one and/or multiple impacts on a given spot. In order to take advantage of the device and turn it into apparatus for scientific use, it is necessary to instrument and characterize it, then quantify each phase of its operation. A control microcomputer manages marking via a software. Impacts are carried out by the movement of a cermet point intro- 


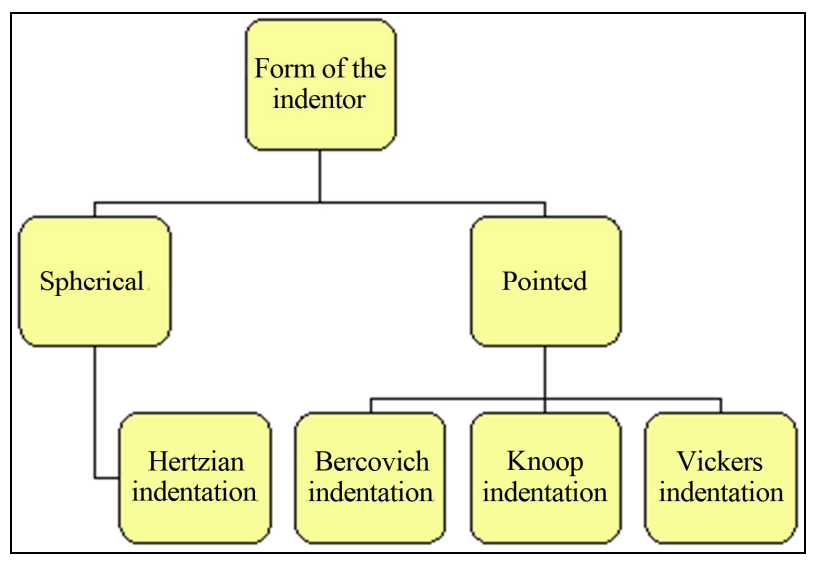

Figure 1. Various types of the indentor.

duced into the stylus. Figure 2 shows the principle of the micropercutor device.

\subsection{Impact Achievement}

The purpose of the impacts is to induce plastic deformations (the very principle of marking) in metal, and to repeat the impacts in a given point, which allows the fatigue study of material in the mode of controlled impacts. The samples are placed in a specimen carrier specially designed to avoid any vibration during the impacts. Once the sample is fixed, impacts are carried out according to the required conditions: placing the right diameter of cermet point $(2.3 \mathrm{~mm})$, introducing the coordinates of the impact point on the surface of the sample, choosing the number of impacts to be carried out, introducing the vertical and horizontal distances between each point of impact indicated by the software (one always using values set at 0 ), selecting the automatic acceleration indicated in the marking software, adjusting the impact height $(H)$ : distance between the sample surface and the point $(H=1 \mathrm{~mm})$, and choosing the number of cycles of impacts to be carried out $(500,1000,5000,10,000$, and 20,000).

\section{EXPERIMENTAL PROCEDURE}

\subsection{Test Conditions}

The micropercussion tests were carried out under the same conditions for all the samples:

-The spherical cermet impactor of radius $R=2.3 \mathrm{~mm}$ and impact speed $V_{\mathrm{i}}=0.5 \mathrm{~mm} / \mathrm{s}$.

-Force of impact: $F=142 \mathrm{~N}$ and frequency of impacts: $f=20 \mathrm{~Hz}$.

-Number of cycles of impacts: 50, 500, 1000, 5000, 10,000 and 20,000 .

-Lowering time $t=10 \mathrm{~ms}$.

The steel used is heat-resisting $\mathrm{X} 6 \mathrm{Cr} 17 / 1.41$ steel; its chemical composition is presented in Table 1.

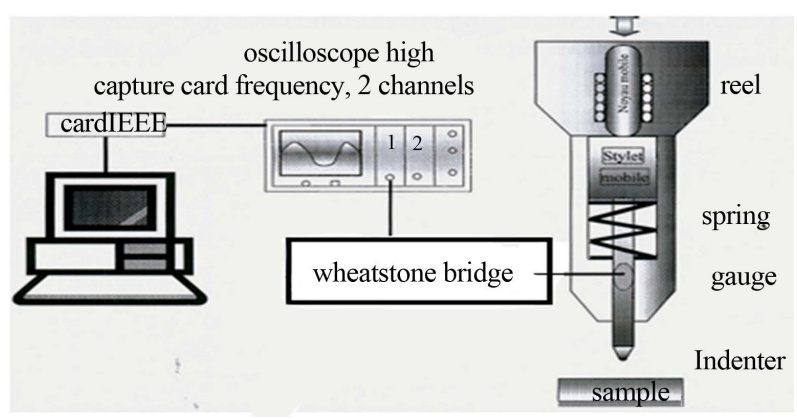

Figure 2. Principle diagram of the micropercutor.

Table 1. Chemical composition of X6Cr17/1.41 steel.

\begin{tabular}{cccccc}
\hline Element & $\mathrm{C}$ & $\mathrm{Si}$ & $\mathrm{Mn}$ & $\mathrm{P}$ & $\mathrm{S}$ \\
\% in weight & 0.0582 & 0.049 & 0.309 & 0.054 & 0.0279 \\
Element & $\mathrm{Cr}$ & $\mathrm{Mo}$ & $\mathrm{Ni}$ & $\mathrm{Al}$ & $\mathrm{Cu}$ \\
\% in weight & 16.94 & 0.811 & 0.002 & 0.04 & 0.025 \\
Element & $\mathrm{V}$ & $\mathrm{Fe}$ & $\mathrm{N}$ & $\mathrm{B}$ & \\
\% in weight & 0.0638 & 82.09 & $>0.06$ & $<0.005$ & - \\
\hline
\end{tabular}

\subsection{Microscopic Observation}

There were two observations of impacts:

-First, a top view of the indented part, which furnishes total information of the impact and its diameter before cutting and coating (Figure 3 represents the sight of top of the impacts).

-After cutting, polishing and chemical attack, a second observation concerning measurements of microhardness of the bottom of the impact (the Figures 4(a) and (b) represent the detail of a print of microhardness).

\section{RESULTS AND DISCUSSIONS}

\subsection{Diameter of Impacts}

The diameter measurements are shown in Figure 5. Three stages can be distinguished in this curve. At the first stage (50 - 500 cycles), it was noticed that the diameter increases with the increase in the number of cycles (i.e. that the effort of the impact sustained grain damage). At the second stage (500 - 10,000 cycles), the diameter had a slight reduction because of the rise in the temperature caused by the repeated shocks. The deformed zone slightly becomes ductile. At the third stage $(10,000-20,000$ cycles $)$, the increase in the diameter of the impact is ascribable to the creation of fresh workhardening, which is a confirmation of a stable plastic deformation.

\subsection{Microhardness Measurement}

The median value and the maximum value of the 


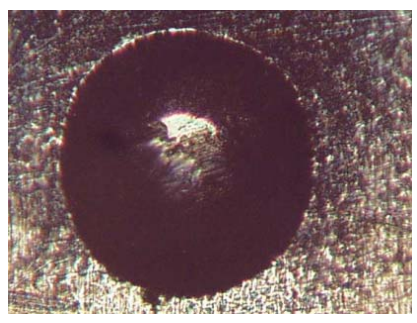

50 Cycles $(50 \times)$

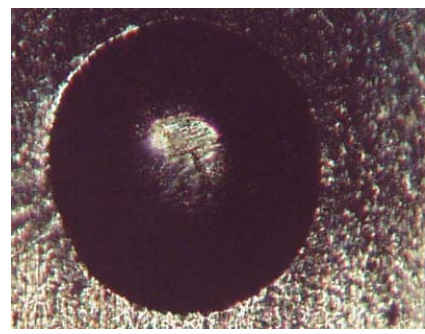

1000 Cycles $(50 \times)$

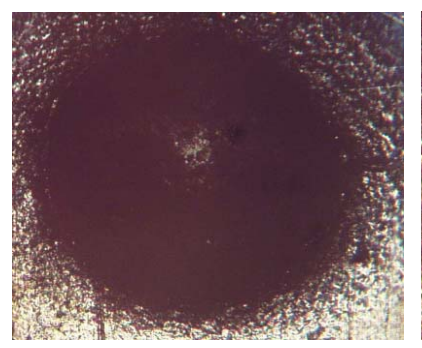

10,000 Cycles $(100 \times)$

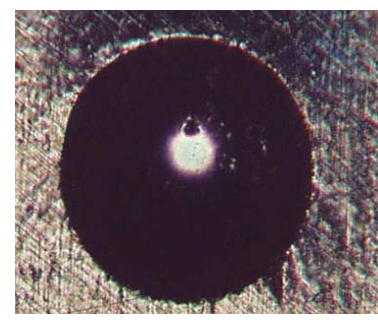

500 Cycles $(50 \times)$

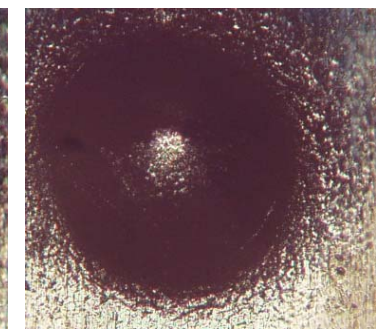

5000 Cycles $(100 \times)$

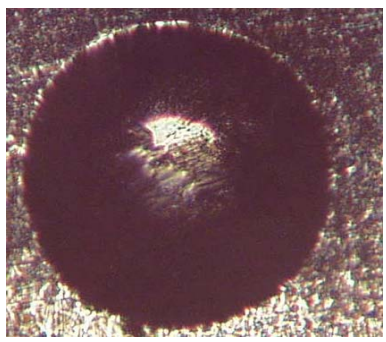

20,000 Cycles $(100 \times)$

Figure 3. Sight of top of the print before cutting and coating (Ajouter l'échelle).

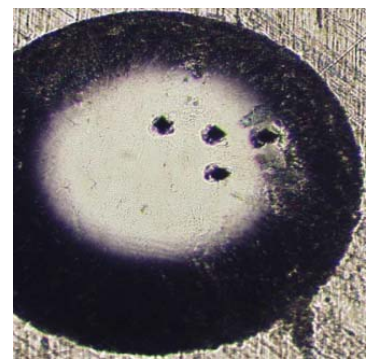

(a)

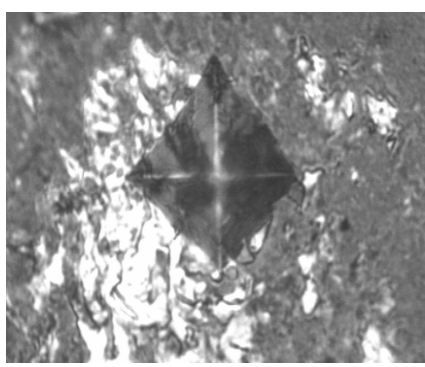

(b)
Figure 4. Sight of top of the prints of the microhardness. (a) $(25 \times)$; (b) Detail $(100 \times)$.

measured microhardness taken on the surface part of the bottom of the impacts left by the shocks repeated for various cycles are represented by Figure 6. The two curves have the same appearance, which is also characterized by three stages. Stage I (50 to 1000 cycles): one sees that the microhardness $\mathrm{Hv}_{(0.1)}$ increases from $176 \mathrm{Hv}$ to $215 \mathrm{Hv}$ in the first case and from 178 to $222 \mathrm{Hv}$ in the second case, that explains the elastic domain. Stage II (1000 to 10,000 cycles): the microhardness decreases a little because the stainless steel changes its structure under the effect of the heating from where we note a certain

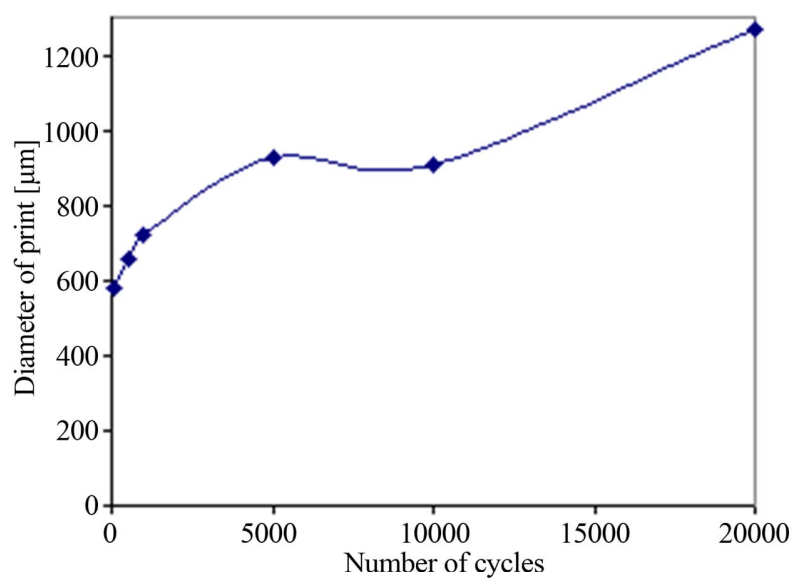

Figure 5. Evolution of impact diameter according to cycle number.

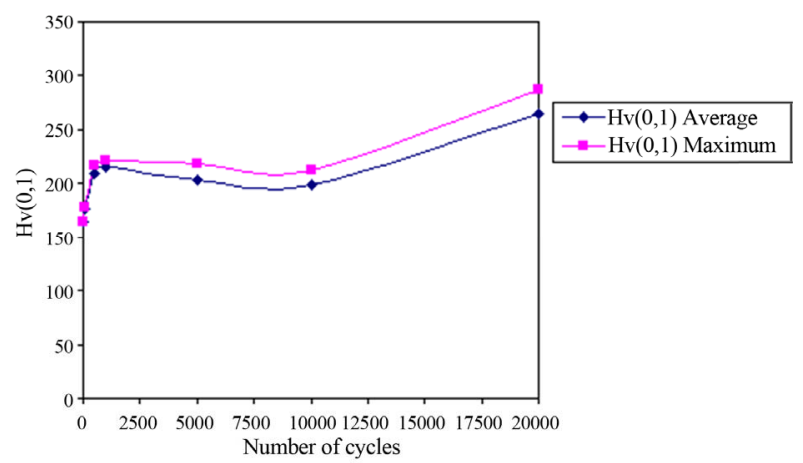

Figure 6. Variation of the surface microhardness according to the number of cycle.

ductility. Therefore, one can say that one is in an elastoplastic state. Stage III (10,000 to 20,000 cycles): steel underwent, under the effect of an additional considerable heating at the previous stage, a work hardening. In this case, the plastic deformation east is established. The hardening of ferritic stainless steel is attested by the values of the microhardness, which exceeds $265 \mathrm{Hv}$ for the first stage and $287 \mathrm{Hv}$ for the second one. The test of microhardness is carried out under a load of $0.4 \mathrm{~N}$ on the deformed zones cut transversely. For each set of impacts (stage I, II and III), one carried out a profile of microhardness. Figure 7 represents the profiles of microhardness according to the depth of the impacts for each set of measurements. It reveals that the microhardness values are close (almost equal) - whatever the depth and the number of cycles, except for the case of 50 cycles. In the later case, the microhardness increased slightly to 100 $\mu \mathrm{m}$ depth, probably due to the structure. This increase is not very significant because it is within the range of tolerances, which proves that the work hardening zones are almost homogeneous in depth. To understand the behavior of the material undergoing repeated shocks by hard particles, some authors [11-12] have studied the different 


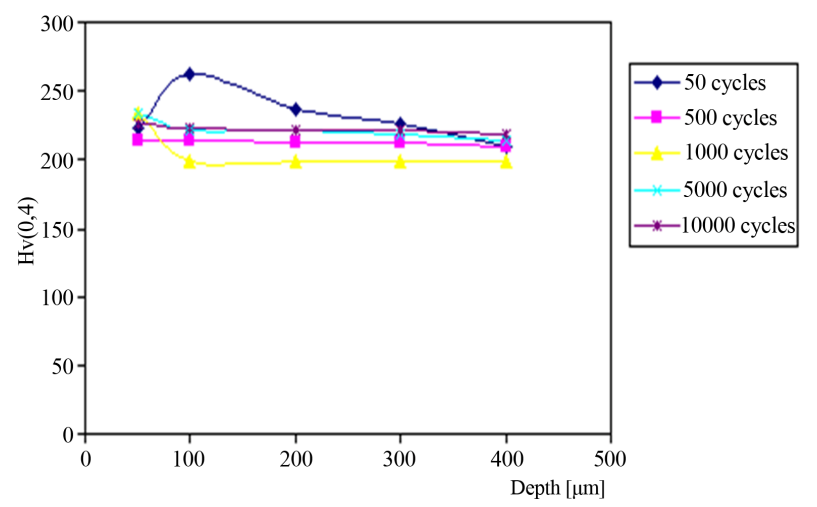

Figure 7. Profile of microhardness Hv (0.4) according to the depth of the impacts for each cycle.

types of contact, fretting, deformation and indentation.

\section{CONCLUSIONS}

The effect of the shocks repeated by microindentation caused physicochemical and metallurgical transformations under the effect of the kinetic energy, such as the lack of texture (work hardening) and the variation of the microhardness. We notice that the ferrite stainless steel studied, which is close to the nuance of steel $\mathrm{X} 6 \mathrm{Cr} 17$ 1.41, goes through three principal stages: the first stage (50 - 500 cycles) is an elastic domain, the second stage (500 - 10,000 cycles) is an elastoplastic domain and the third stage $(10,000-20,000$ cycles) is a plastic domain (work hardening).

We have seen that the effect of microindentation caused a tribological transformation of a ferritic stainless steel. Thus we can conclude that our steel has gone through three main stages:

-The first stage (50 - 500 cycles):

The metal changes from elastic to elastic-plastic state and becomes very ductile. The micrographs show the existence of grain boundaries in the deformed zones.

-The second stage (500 - 10,000 cycles):

All parameters of the TTS (diameter, depth of the prints and microhardness) decreased slightly, which leads us to assume that the metal is in the elastoplastic domain.

-The third stage (10,000 - 20,000 cycles):

At this stage, the microstructure changed completely, as we see the lack of texture in the impacted zones, which means that these areas are completely cold worked, particularly for 20,000 cycles where the plastic deformation is permanent.

\section{ACKNOWLEDGEMENTS}

We are grateful to the Laboratory of Tribology and System Dynamics ECL, France for the cyclic indentation tests (micropercussion) and the physics laboratory for mechanical and textile-UHA-Mulhouse, France for Microhardness tests.

\section{REFERENCES}

[1] Bensimon, R. (1971) Steels, Tome. 1st Edition, P.Y.C.E, Paris.

[2] Chaussin, C. and Hilly, G. (1992) Alloys. Edition Dunod, Paris.

[3] Cunat, P.-J. (2000) Creep-resistant steels and stainless steels. Technical of engineer M4540.

[4] Sekkal, A. (2000) Study of surface tribologicals transformations or STT induced by controlled energy impacts. Thesis, Central School of Lyon.

[5] Dominique, F. (2000) Hardened test. Technical of engineer M123-1.

[6] Farah, L., Coquillet, B., Vannes, A.B. and Azzi, A.R. (2002) Study of the mechanical behavior of an austenitic stainless steel under repeated shocks. Journal of Matériau \& Technical, 1-2, 31-36.

[7] Gachon, Y. (1997) Study of erosion by solid particles of PVD multilayer coatings on metallic substrates (base titanium). Thesis, Central School of Lyon.

[8] Johnson, K.-L. (1985) Contact Mechanics. 1st Edition, Cambridge University Press, Cambridge.

[9] Gampala, R., Elzey, D.M. and Wadley, H.N. (1994) Plastic deformation of asperities during consolidation of plasma spayed metal matrix composite monotype. Acta Metallurgica \& Material, 42, 3209.

[10] Sauger, E. (1997) Contribution to the study of the tribological surface transformation in fritting. Doctoral Thesis, INSA of Lyon.

[11] Shimizu, K. and Noguchi, T. (2011) Mechanical properties of solid particle erosion and stainless steel at elevated temperature. Wear, 271, 1357-13645.

[12] Saada, G. (1980) State metal plastic deformation. Technical Engineering, M45, 1-25. 